\title{
Of Mind and Matter: the archive as object
}

\begin{abstract}
Archives are not only sources of evidence and information; they are also material objects with physical, tangible characteristics such as size, weight and colour. Moreover, the way in which researchers and visitors to archives respond to them may not just be intellectual, but sensory and emotional as well. Despite this, it is the informational content of archives which is routinely given prominence over their material properties. In this article, I discuss some of the recent literature regarding the physical and material properties of archives and consider why and how their materiality is often unacknowledged. In considering our response to archives, I argue that our engagement with archival records is a holistic experience, in which cognitive and physical reactions shape one another. Using the concept of the 'body schema' as a tool to understand how these reactions occur, the paper frames these discussions around specific examples of exhibited archives at the Petit Palais in Paris.
\end{abstract}

Keywords: materiality; phenomenology; engagement; exhibition; body schema

\section{Introduction}

The exhibition The Art of Peace: Secrets and Treasures of Diplomacy was on display at the Musée des Beaux-Arts de la Ville de Paris, housed in the Petit Palais in central Paris, between 19 October 2016 and 15 January 2017. Organized by the French Ministry of Foreign Affairs and International Development, its main focus was a discussion of the concept of peace, particularly from a French context, and how this has been promoted, transformed and adapted over time. The press release for this show described it as 'an ambitious, ground-breaking exhibition', ${ }^{1}$ with an emphasis placed on the display of a significant selection of documents held at the diplomatic archives which have not been on public display before. 
I visited on a very wet and cold day just before the exhibition closed in midJanuary. Having walked through the stately baroque hallways of the Petit Palais, I made my way through the exhibition galleries, taking in the various display cases showing treaties, charters and diplomatic letters, framed by paintings and sculpture which contextualized these texts within the wider literary and artistic readings of the times. The fourth room in the exhibition, 'Diplomatic Treasures', was substantially different from the gallery spaces which preceded it. An enclosed, small, low-ceilinged, polygonal room, necessarily dark to conserve its exhibits, yet drawing attention to the well-lit wall cases, this space presented royal and state correspondence, diplomatic documents between ambassadors, and treaties of which France was a party. Here, there were no pictures or other artwork for the visitor to admire; instead, attention was focused purely on the documents themselves. The introductory caption to this space immediately drew my attention to the dual performativity of these documents: not only as sources of great historical value ('drawn up according to strict protocols') but also their 'sheer beauty': their 'elaborate calligraphy, illuminations and seals' described as 'true works of art'. ${ }^{2}$ In essence, I was being alerted to recognizable but often unacknowledged characteristics of archives: they are, indeed, sources of information, but they are also objects, with tangible, physical qualities which can elicit and stimulate both cognitive and sensory responses.

On entering this enclosed space, I was aware of some intriguing and striking documents whose visual qualities compelled me to look closer: the enormous red wax seal hung on wires of silver and red silk appended to the agreement between France and Britain over Newfoundland and parts of Africa, 1904; the decorative coloured inlay work on the letter of the King of Morocco to Louis XVI written at Meknes in 1774; the huge rolled capitulations written in ink and gold by the Sultan Mehmed IV at Edirne in 
1673; the incredible sea of seals attached on gold and silver twisted cords to the act of declaration of the election of Henri of Valois, King of Poland, by the Polish nobility in 1573. Elsewhere were brightly coloured and decorative documents from the tsarist court in Russia, the Shah of Persia and the Venetian republic. And seated - reclining, even - beneath a glass shade in the centre of the space was an 1861 letter from Rama IV, the King of Siam, to Napoléon III, engraved on gold leaf, the caption describing its presentation to the emperor and empress in a lavish ceremony at Fontainebleau. Each of these exhibits attracted attention not only because of their content but also for their appearance.

This exhibition space, then, enabled a range of different responses for the visitor. As I moved out of this gallery and entered the final parts of the exhibition, I was left with a number of differing thoughts and feelings. I had learnt something about the part played by France and other nations in the entangled history of alliances and negotiations over the centuries; and more broadly of the French Ministry of Foreign Affairs' archive in managing and preserving these records to enable these (and other) narratives to be told. I had learnt about the specifics of individual treaties and the power and prestige provided by the giving of metal-encrusted charters and gold letters. But there was something else as well, less easy to articulate: the feeling of sensory engagement afforded by the material properties of the documents on display, an emotional feeling associated with design, form and shape, as well as content; and a sense of resonance and awe from being in their presence. The documents by their very nature have characteristics which they all share and which archivists are fundamentally aware of: content, context and form. Each of these characteristics produces signals which can trigger in their viewers both intellectual and emotional responses in a tangled sharing of experiences. 
In this article, I try to unpick some of these intellectual and emotional reactions, to understand in more detail the nature of how archives can be utilized and responded to, and to contribute to the growing literature on archival materiality. I begin by discussing some of the recent literature concerning the material properties of archives and how this has developed in light of trends around increasing digitization and the proliferation of born-digital records. From here I try to discuss how researchers and visitors to archives experience archival records both intellectually and materially. In particular, I draw on research into and ideas around embodied experience to show how the body plays a fundamental part in our understanding of perceived phenomena, and how our cognitive awareness of such phenomena is irresolutely tied up with our physical, sensory and proprioceptive experience. Finally, I return to The Art of Peace to explore some of the ways in which the archives on display can enable complex readings which utilize both intellectual and material understanding in an entwined and bundled way.

\section{Discussions on archival materiality}

In her discussion of the study of diplomatics, Luciana Duranti describes how 'a document has an external makeup which is its physical form, an internal articulation which is its intellectual form, and a message to transmit which is its content. It is impossible to understand the message fully without understanding the makeup and articulation which the author chose to express it'. ${ }^{3}$ Although diplomatics has been understood to apply only to documents in an official or juridical context, its scope has widened over time to be considered applicable to all types of documents; ${ }^{4}$ in effect, these three characteristics - a physical form, an intellectual form and content - are essential to all forms of document. Yet it is the content - and, arguably, the intellectual form of this content - which has been, and largely still is, of most interest to those who 
work with archives. Maryanne Dever acknowledges this when she writes of how 'dominant practices for literary and historical research conducted within archival collections privilege the texts found on documents and pay considerably less heed to the material supports for those words and markings, as though papers and pages can be understood as neutral containers or platforms for the transmission of such texts' ${ }^{5}$ She goes on to write that 'We are supported in our indifference to the embodied nature of archived documents by practices of archival description that traditionally focus on the scope, scale and information content of collections, while giving only the most perfunctory account of the physical state of a fonds: metres of shelf space, numbers of boxes or folders, numbers of pages' ${ }^{6}$ Karl Magee and Susannah Waters similarly note that working with artists and designers 'served to highlight that most archive catalogues do not include detailed information about the physical attributes of the items they describe, e.g. the techniques and materials used to create archive items, their colours and any visual motifs present (such as stamps or annotations)' ${ }^{7}$ In effect, the evidential and informational attributes of archives are what largely determine how they are described and accessed. The physical forms of such archives only enable the content to be used.

This emphasis on the content of records to the apparent exclusion of any literal appreciation of form has not always been the case. Cornelia Vismann writes of how Renaissance travellers collected texts, and how they studied them, not for their content but rather for their material properties; it was the parchment and ink, the handwriting and typography, the seals and stamps, and their provenance and history, which proved to be of interest. ${ }^{8}$ Interestingly, she notes how the disciplines of palaeography and diplomatics, the focuses of which include the material attributes of archives, were 'reduced to the status of mere ancillary sciences' in around $1900 .{ }^{9}$ This resulted 
because of a shift away from an interest in the material properties of documents to one which asserted the primary importance of content: 'From that point on, mediatechnological textual analyses were made to assist historiographical factual analyses'. ${ }^{10}$ The emphasis on content and information has led to an increasingly occluded appreciation of the material, which as a result has not been the subject of much discussion in the literature until relatively recently. Dever provides some specific reasons for this: an emphasis on research results rather than the process or methodology of researching itself; a lack of recognition of material properties within the current standards for archival description; and emphases on descriptive literalism and on transcription. ${ }^{11}$

Much recent discussion concerning archival materiality has arisen largely as a result of increased digitization and the profusion of born-digital records. ${ }^{12}$ Many practical concerns have developed from these conversations, including the ability of digitization to capture successfully the physical characteristics of an archive; the perceived loss or gain of the original record's 'aura'; and the opportunities that digitization can provide to enhance meaning and understanding. ${ }^{13}$ Maryanne Dever, in particular, draws attention to how increased digitization was initially perceived as a threat to the 'culture' of paper, but notes that 'rather than the digital forever cancelling out or superseding paper and paper formats, a culture of co-existence has emerged... we are witnessing not the death of paper, so much as paper's long afterlife'. ${ }^{14}$ Dever goes on to talk of 'heightened materiality,' ${ }^{15}$ an increased awareness of the materiality of paper which arises at the moment of its imminent or actual loss. She cites examples of real loss of archives: the collapse of the archive repository in Cologne in 2009, and the partial destruction of libraries in Timbuktu in 2013; but also relates it to the perceived loss of paper which increased digitization seems to bring. ${ }^{16}$ In effect, the 'digital turn' 
has presented opportunities to reconsider and rethink the nature of archival materiality. When the researcher, increasingly used to a more digital environment, interacts with material, physical archives, there can be an increased, heightened awareness of being in the presence of paper, so unfamiliar has it become. ${ }^{17}$ As Dever writes, '[there were] fears that the presence of digital surrogates might constitute grounds for dispensing altogether with the preservation of analogue originals', yet there has in fact been renewed interest in 'what it means to work with original documents' ${ }^{18}$

The 'digital turn', then, has enabled a rediscovery of the material property of archives, but poses the question of why these physical characteristics are so often - and so easily - discounted in contrast to the intellectual content of the record. Such a question can be considered through an analysis of the material aspects of documents themselves and an examination of the eliding characteristics between text and object. Dever writes of 'the overwhelming tendency of so many researchers to experience paper as something that simply disappears before our eyes or slips from our conscious apprehension'; that 'physical documents are rendered transparent and lose their 'bodies'... when their materiality is obscured, 'disappeared' or simply not seen'. ${ }^{19}$ Although this observation subtly places emphasis on the researchers' own experience of the record, it also unlocks a phenomenological characteristic of the document itself which helps us to understand how these experiences are rendered. This focuses on the document's role as mediator, which shapes our perception of what we see. Drawing on anthropological writing can help develop these ideas. Patrick Eisenlohr observes the 'phenomenological quality of media that seems to contradict media constructionism and generativism. This is the tendency of media to disappear in the act of mediation. In fact, media can only function as such if in the act of conveying something they are also capable of drawing attention away from their own materiality and technicality in order 
to redirect attention to what is being mediated'. ${ }^{20}$ Annelise Riles notes 'the capacity of documents to place their own agency in abeyance, such that what is made visible in the document, rather, is the creativity of another agent'; ${ }^{21}$ in other words, what has been written - and the subject of such writing - becomes visible to the observer rather than the design or form of the writing or the document itself. In effect, the materiality of archival records can be subsumed by a more purposeful consideration of their content. Consequently, material properties of records are often ignored and overlooked.

The materiality of the document can add layers of intellectual meaning and understanding which may enhance or even contradict its content. ${ }^{22}$ Recognizing the knowledge that can be gleaned from the record's material properties enables a more holistic understanding of its history, and can facilitate a more nuanced and deeper interpretation of its content. Ala Rekrut discusses this when she writes:

\footnotetext{
Archival records, whether born digital or analogue, are material culture; they are material traces of events and actions arising from within particular historical contexts. Historical records are rooted in the personal and social circumstances surrounding their creation and they are physically embodied in the materials that constitute and support the written text or images. Records are products of their times and every physical component has a complex socio-cultural and technological history; they have been participants in events in the histories of science, technology, industry and economics. The sizes, shapes and weights of records structure physical interactions between records and their users, and changes in their presentation and physical condition may provide evidence of their histories of use and stewardship. ${ }^{23}$
}

These considerations recognize the intellectual understanding that the record's physical properties may provide: insights into the social, cultural and economic context of the time when the record was created, helping to shed light on the society that made it. Similarly, the physical characteristics of the record will bear the traces or marks of time, enabling understanding of the record's provenance and use. The document's form 
gives us opportunities to question its purpose, as both instrument and as source of information. ${ }^{24}$

These phenomenological attributes of the archive can also shape other forms of engagement and understanding. Archives are material objects, with tangible properties, and as such they can elicit responses from users. Such a concept can be placed within a wider phenomenological understanding of objects. This recognizes the physicality and tangibility that objects possess, and the range of responses that their different, physical characteristics can instil. ${ }^{25}$ As Sandra Dudley comments, 'the sensory and emotional engagement with [an object's] physicality... [can be] a potent and sometimes transformative phenomenon... the physicality of the object... can trigger personal, emotional and sensory responses that may have a significance of their own as well as in enhancing subsequent understanding'. ${ }^{26}$ What is key here is that the archive's materiality may encourage responses which may not be intellectual or cognitive at all; instead, they may be rooted in sensory responses - the look, feel, smell of the document - and in emotional experiences. The material properties of a document can elicit information and understanding around creation and use; but they can also provide emotional, sensory, even - as Sandra Dudley notes - 'visceral' ${ }^{27}$ reactions. In acknowledging these forms of engagement, it is also important to note that whilst the textual content can provide intellectual meaning, it too can also encourage emotional responses: consider the excitement of a seaside postcard, or the tragedy of a wartime telegram.

When we discuss these different forms of responses to archives, it is easy to compartmentalize them: 'intellectual', 'sensory', 'emotional'. Indeed, on the one hand, the archive as information source, a mediator whose materiality is suppressed in order to convey a message and, on the other hand, an object possessing phenomenological 
characteristics, suggests a dualistic performativity, a bifurcation between the document's perceived role as information and as object. Yet, I want to argue that the way we engage with archives cannot be reduced to simple categories, acting seemingly exclusively of one another; rather that these experiences are entwined and bundled. As we have seen, the content of the document can encourage both cognitive and emotional readings, whilst its physicality can elicit both intellectual understanding and sensory engagement. What is key is that our perception and engagement with source and object both happen at the same time; following Matthew Hull, it can be argued that the material property of the document can shape not just possible sensory responses but also how the textual content is understood or read. ${ }^{28}$ Rosemary Sassoon's 'tense or relaxed' writer who puts pressure on the page, or whose handwriting betrays age or emotion; ${ }^{29}$ or Ann Laura Stoler's colonial government archives, 'condensed sites of epistemological and political anxiety': ${ }^{30}$ these may affect not just what we know about how these documents were written, but also how we feel, react, respond to them. Our understanding of what has been written has been influenced by how it was written. Similarly, the texture, feel or smell of the document can influence how we respond to the words written on the page. In turn, our emotional response can be directly influenced by what has been written and so our response to the document as object is shaped by the words inscribed on it. In effect, the content and the material are entwined in a close synergy, acting upon, affecting and shaping meaning around the other. The response to a document's materiality exists at the same time as a cognitive understanding of it; the emotional, sensorial, cognitive and intellectual are all bound within the informational and the material together, shaped and shaping each other as part of a collective whole. 
To help us comprehend this holistic and global response to archival documents and, more widely, to other object phenomena - it is useful to draw on studies which examine the human experience, and consider how our bodies engage with the world in an entwining of cognitive and bodily reactions. Such studies draw on a range of disciplinary fields, including both phenomenological and neurological research. ${ }^{31}$ Shaun Gallagher, writing about how the mind and the body are involved in the understanding of the self and the perception of others, writes of the concept of Cartesian dualism that continues to persist in much writing on this topic. This is a notion that awareness of one's own body and the world around us happens in the brain and that the body has no role to play in this. He describes the commonly used image of a brain in a vat, able to understand human interaction fully, separate to a body (or, at least, possessing a nervous system which is not in any way linked to the body). ${ }^{32}$ In a gallery setting, Brian O'Doherty's discussion of the 'white cube' leads to an understanding of the 'Eye' and the 'Spectator' or body; a divided experience albeit one with 'a double function'. ${ }^{33}$ Yet if we recognize that our response to archives can be both cognitive and sensory, then we can perceive a bodily, physical understanding of archives simultaneously and collectively with an intellectual one; indeed, one in which the body itself moulds the experience of the brain. This concept follows the work of Gallagher, who writes: 'Across the Cartesian divide, movement prefigures the lines of intentionality, gesture formulates the contours of social cognition, and, in both the most general and most specific ways, embodiment shapes the mind'. ${ }^{34}$

Gallagher writes about the concept of the 'body schema', a system of processes within the body that enables the body to position itself and to move in order to accomplish a perceived objective. The body schema is a 'system of sensory-motor functions that operate below the level of self-referential intentionality'. ${ }^{35}$ It uses 
nervous impulses and signals from proprioceptors, or sensory receptors in the muscles, tendons and joints that respond to stimuli within the body, in order to locate and comprehend the position of the body's limbs, its posture, balance and movement. This system happens in what Gallagher describes as a 'close to automatic' way, which means that it does not happen as a reflex action: the behaviour or intention of the individual shapes the movements that are controlled by the body schema. ${ }^{36}$ 'It is important to note that although a body schema is not itself a form of consciousness, or in any way a cognitive operation, it can enter into and support (or in some cases, undermine) intentional activity, including cognition. ${ }^{37}$ Actions that the individual wishes to achieve are enabled through the body schema, but the actions of and the operating of the body schema is such that the individual is not (fully) aware of them. Attention is focused on achieving the objective and not the physical accomplishment of such an objective: when walking, for example, my thoughts focus on my destination, rather than the action of putting one foot in front of the other. The body schema operates prenoetically, in that it 'helps to structure consciousness, but does not explicitly show itself in the contents of consciousness'. ${ }^{38}$ This prenoetic experience enables us to interact with our environment in a way that we are (largely) not conscious of, in a way which means that we do not have to think through the action of movement or balance. Our body schema enables our bodies to interact with the environment around us and focuses attention on this rather than on our bodies themselves. ${ }^{39}$

The body schema therefore shows how our bodies respond habitually to our environment, not only in order to accomplish an objective which has been intellectually conceived, but also to influence and shape how we behave and move, which may - but not always - be perceived in cognitive understanding. Importantly, the concept of the body schema helps show how we respond to our environment both physically and 
intellectually, and how these responses both influence and shape each other. Both our intellectual intent and our 'body-schematic performances' ${ }^{40}$ operating in a semiautomatic and prenoetic way, influence each other, and in turn shape our movements, mood, feelings, thoughts and actions.

Our engagement with phenomena such as archives can therefore be understood as a process by which different experiences all shape our reactions and responses. Our perception of and responses to archives are part of how our bodies themselves experience and engage with our environment. Our behaviour, actions and thoughts are not compartmentalized but rather collective experiences, influencing and affecting one another to form a comprehensive whole.

How we respond to archives can therefore be seen within this context. The response to a document - its age, rarity, appearance and content - is not accomplished through a cognitive understanding of that document which then shapes an emotional or physical response, but rather through the body interacting prenoetically with the document and shaping the way we come to understand how we perceive it. 'It is not that perception predates emotional reaction, but that affect already shapes perception. ${ }^{41}$ Following Gallagher, it is possible to suggest that by looking at a document whose age and beauty produces a sense of awe, the understanding of 'awe' has already been shaped by the bodily perception of the document, rather than the document being perceived and the viewer deciding that it inspires awe. ${ }^{42}$

Whilst our experience of archival documents is an entwined bundle of sensory and cognitive responses, as understood through an analysis of the body schema, the particular forms that these responses take can and will vary between different people. The nature of the engagement will be influenced by the personal and social experiences which we bring to bear on it. Following Suzanne MacLeod, our personal identity, our 
memory, our social experiences and relationships with the world as well as our understanding and knowledge will all shape and influence how we engage with phenomena such as archives. ${ }^{43}$ The way in which we may experience archives or how archives themselves may be understood to perform or interact with us is personal to everyone, shaped by our own ontologies and moulded through a broad range of personal and social experiences.

\section{The Treaty of Friendship}

In returning to The Art of Peace exhibition in Paris, we can look at two specific exhibits and consider how they may be understood by the viewer. In this way, it is possible to unlock some of the ideas around the phenomenological properties of archives.

Acknowledging the role of the body schema in both instances, each draws on a broad range of personal meaning-making which demonstrates some of the affordances that the material and intellectual properties of archives can enable. The first places emphasis on the performativity of the document itself, whilst the second draws on both intellectual and emotional constructs which I as the viewer bring to the document.

The Treaty of Friendship between France and Peru, 1861, is bound in velvet, applied with copper, zinc, nickel and gold in the form of flowers and bees. Whilst I was drawn to the delicate craftwork and the touch of the velvet - I could almost reach out and stroke it - the caption also told me that the elaborate ornamentation is a reminder of the importance placed on the recognition given by 'Western nations' to the Peruvian state ('La virtuosité du décor de ce portefeuille atteste d'une aspiration á la reconnaissance de l'État péruvien, indépendant depuis 1824, par les nations occidentales ${ }^{44}$ ). The material characteristics of the document were not only able to stimulate sensory responses, they also helped me to appreciate the archive as an object; 
they alerted me to the intellectual integrity and significance of the document, reasserting its message and drawing attention to its status.

The desire to touch the object in this context can belong to a prenoetic understanding of how the body shapes the way in which we perceive objects and how we think about and respond to them. Drawing on a range of studies into this area, Gallagher describes how vision engages neurons in the brain 'responsible for the motoric encoding of actions such as reaching and grasping'; interestingly, this happens 'even when we are not specifically required to reach for... or pick...up' the object being observed. The perception of such objects is shaped by the brain in this way; this 'form[s] part of what it means to perceive such objects'. ${ }^{45}$ Although I cognitively comprehend the desire to touch the velvet binding of the document, this response has in fact already been shaped and enfolded by my body; my body has recognized and readied this form of interaction. As such, the notion of a sensory response - of feeling and touching - and the cognitive recognition of this response - as well as the knowledge that I would acquire from touching the binding - are intricately and inseparably bound together. My engagement with the document not only happens at both a material, physical level and at a cognitive one, but the bodily response to the document actually enables the intellectual responses to occur. In effect, both responses - physical and intellectual - happen together, and are shaped by one another.

The document records the recognition agreed between the two countries: its content articulates and evidences the actions that have taken place and, combined with its contextual, intrinsic and extrinsic characteristics, imbues the treaty with 'recordness'. As an object, however, the document also performs the actions that it articulates; it is itself a performance of diplomacy. Its material physicality roots the actions it describes in a fixed, nodal moment which enables the action of diplomacy to be carried out; its 
very presence expresses the moment of agreement. This may be enhanced through striking visual characteristics, but it need not be: its structure, size and weight; simply, its very presence, embodies the action itself. The document becomes performative, its physicality the 'technology' through which the act of diplomacy is achieved; it is an instrument of action. ${ }^{46}$

The record as instrument can be seen in many types of documents. The enacting of the record as instrument is achieved not only through its content, which evidences what has occurred, but also through its materiality, which performs the function of enactment or action. In the case of the Treaty of Friendship, the velvet binding and the metal decoration enhance the importance of the textual content, but they also enable the record to perform as an act of diplomacy in its own right; it performs the action itself. Consequently, the treaty does not simply record the moment of friendship agreed between France and Peru; it is this moment; its physicality and its presence are the action of diplomacy. The presence of the document as an expression of the diplomatic intention of its makers asserts the document as an 'objective embodiment' of their will; ${ }^{47}$ it becomes, in Alfred Gell's words, 'an emanation or manifestation of agency', although such an analysis stops short of accepting his assertion that this emanation is ' $\mathrm{a}$ source of such potent experiences' that the object itself becomes 'a self-sufficient agent' ${ }^{48}$ As Howard Morphy comments, objects acquire agency only when people use them; 'hence objects have no agency themselves but only with respect to the ways in which they are used by people'. ${ }^{49}$ The performativity of the document, then, is not an assertion of the document's own manifest agency, but rather the embodiment of its author's intentions, again, following Gell, an artefactual index of both origin and reception. $^{50}$ 
The materiality of the document transmits the value that has been inscribed upon it both by its creator and by its recipients. As such it not only embodies the intentions and wishes of its creator but also the value and importance that its creator has placed upon it. Moreover, in citing Gell's understanding of the anthropology of art, the document embodies a 'social relationship' between itself and its recipients who, as 'patients', may be affected by it or, as 'agents', enable it to 'have come into existence' in the first place. ${ }^{51}$ As such, the document embodies not only its creator's intentions, but also its relationship with its recipients, and now, potentially and by extension, its relationship with its audience in its role as exhibit. Such an embodiment by its very nature rests in its physicality as much as its content and it is through its embodied presence that these readings can be transmitted to its audience. This transmission is articulated through both the document's physical and textual characteristics; the document, as a bundled or braided object, performs its role of diplomacy - and now its role as exhibit - not only by its textual readings but by its physicality as well.

\section{The Cartulary of Christopher Columbus}

The cartulary of Christopher Columbus, one of only two remaining copies (of the original four) which attest the titles and privileges conferred on him by Ferdinand and Isabella of Spain before his last voyage to the Americas in 1502, is a bound volume which was exhibited on its title page. This highly decorative opening provides an introductory text written in black and red and employing elaborately designed capital letters as well as richly calligraphic borders. The label for this exhibit noted that the face depicted within a capital ' $\mathrm{E}$ ' in the centre of the page is possibly an interpretation of that of Christopher Columbus himself. ${ }^{52}$

Although this document was not written by Christopher Columbus, and it may not have been owned or even held by him, it is nonetheless associated with him not only 
through its content (which provides the evidential link) but also its materiality, it having been written within a context closely related to him (as well as the monarchs who conferred the rights and titles therein described). As such, this association with Columbus provides an attribute to this document which is inherently bound within both its intellectual and physical properties. It is an object associated with an individual, it was present with him; and it is now present and close to me as the viewer today. Consequently, it provides a temporal link between that person and me; it provides a connection across time. This seems even stronger when that link is between me and the writer; the page is imbued with the marks of the writer which can be experienced today: 'In the lines left upon its surface the handwritten page bears witness to gestures that, in their qualities of attentiveness and feeling, embody an intentionality intrinsic to the movement of their production'. ${ }^{53}$ In effect, the document is an embodiment of one individual's experience. Its physical presence today enables me as viewer to come into contact with that embodied experience and thus, by extension, with that person themselves: the temporal gap between us is somehow reduced by the presence of a document which acts as an artefactual residue of that person's experience. A helpful way of understanding this concept is the notion of 'historical experience' as described by Johan Huizinga, who writes, 'This not completely reduceable contact with the past is an entry into an atmosphere, it is one of the many forms of reaching beyond oneself, of experiencing truth'. ${ }^{54}$ Frank Ankersmit notes that 'All spatial and temporal demarcations have momentarily been lifted; it is as if the temporal trajectory between past and present, instead of separating the two, has become the locus of their encounter'. ${ }^{55}$ Ernst van de Wetering uses this concept when he writes about the process of 'natural aging' in objects, and articulates some of the experience that can be had by engaging with something which exhibits signs of age through its physical and 
material properties: 'By its untouched condition [the object] spans, amazingly, the gap between us and the distant past, and unexpectedly gives us the feeling the Dutch historian Huizinga called de historische sensatie: the propulsion into a direct experience of the past'. ${ }^{56}$ This notion of 'historical experience' can help in understanding how engagement with a document - as a physical object - can enable an experience with the past in a way that is less hindered by the gulf of time. This 'historical experience' is heightened by the presence of a well-known individual or a significant historical event present or expressed in the document itself. It is the intellectual recognition of a 'culturally-valued' ${ }^{57}$ idea which contributes to this experience.

Crucially, this embodied understanding is rooted in both the document's content, which tells of the subject; its materiality, in the traces and marks of the writer and its owners over time; and its physicality, its presence, which enables this experience to be understood today. Likewise, my understanding of the document takes place in both an intellectual and a physical way. The relationship to the document and its subject can be understood prenoetically, and both the intellectual and the bodily or sensory understanding shape one another and exist in a holistic manner. My understanding of Christopher Columbus and his explorations in the Americas is brought to bear in my engagement with the cartulary, but this understanding is shaped and articulated through a sensory and emotional response to the document itself. In recognizing that the document is about and of Columbus, I am able to draw on 'personal and cultural memories and biographies, and to practice and perform a form of reminiscence' ${ }^{58}$ Following Gaynor Bagnall, who writes about performativity at heritage sites, such a response places emphasis not just on cognition, but on emotion and imagination as well. ${ }^{59}$ The intellectual understanding around this document as an 'artefact' of Christopher Columbus and the sense of fascination and awe that I experience on looking 
at it are entwined together and shaped by one another in a manner which utilizes both cognitive and emotional responses, brought to bear by my own personal thoughts and ideas.

\section{Conclusion}

Interaction with a document is a personal experience. Whether the document is experienced as a research tool in an archive search room or as an exhibit in a gallery space, that experience will be particular to the individual, and may contrast greatly with someone else's. Not everyone will experience or feel the same way about the same document, and people will feel differently about a document at different times. ${ }^{60}$ Moreover, the 'cultural value' that is inscribed onto a document will differ between viewers, depending upon their own interests, knowledge and what they perceive to be of importance. ${ }^{61}$ What is worth noting, however, is that there is a potential range of experience embodied within the archive and that we have the capacity to respond to documents on many levels. Cognitive and intellectual understanding is not separate or isolated from sensory, emotional or bodily experiences; they each shape one another and play a part in affecting and influencing how we respond to and understand the material in front of us. Indeed, the role that our bodies play in shaping and articulating how we respond to a document is perhaps more fundamental than we might allow. Shaping and framing our understanding of what we see in a prenoetic way, our bodies play a vital role in how we perceive and engage with archives. The meanings that we derive from our experience with archives are shaped by our personal and social understanding of the world, our knowledge, beliefs and ideas. The body schema forms part of a process whereby the cognitive, physical and emotional responses as shaped through our personality, identity, memory and social experience are articulated and expressed. 
This article has aimed to contribute to the growing discussion on the material properties of archives, and to articulate how the bodily experience is fundamental to our overall understanding of how we respond to and perceive archival objects. In conclusion, it is important to recognize how these differing types of engagement can help researchers and visitors to engage with archives, and how meaning-making can happen not only intellectually, but sensorially and emotionally as well. Consequently, archivists should be alert to the opportunities that they can provide to encourage such a wide range of responses, through catalogues and research tools that acknowledge the material properties of archives, and outreach events and activities which are shaped around different forms of engagement. ${ }^{62}$ In these ways, visitors and researchers are able to experience archives in a deeper and richer way, utilizing all the senses, and recognizing our bodily as well as our intellectual understanding.

This discussion is part of a wider doctoral research project investigating the nature of archival exhibitions, exploring how archives can create innovative and dynamic forms of engagement with documents through exhibition and display. Drawing across a range of interdisciplinary fields, the research aims to bridge concepts of spatial transformation and phenomenological perception, positioning such discussions within wider contexts of organizational change. The research seeks to contribute to growing discussions around visitor engagement by understanding how archives can and are developing new techniques to broaden and diversify audiences, reshaping the encounter with the archive.

Acknowledgments

Thank you to Professor Suzanne MacLeod and Professor Elizabeth Edwards for their comments on an earlier draft of this article, and for the editor and anonymous reviewers for their comments and suggestions. This research is part of a wider doctoral project which is funded by the Arts and Humanities Research Council through the Midlands3Cities Doctoral Training Partnership. 
Bibliography

Ankersmit, Frank. Sublime Historical Experience. Stanford: Stanford University Press, 2005.

Bagnall, Gaynor. "Performance and performativity at heritage sites." Museum and Society, 1, no. 2 (2003): 87-103.

http://www2.le.ac.uk/departments/museumstudies/museumsociety/volumes/volu $\underline{\text { me1/volume1 }}$

Biber, Katherine. "In Jimmy Governor's archive." Archives and Manuscripts 42, no. 3 (2014): 270-281. doi:10.1080/01576895.2014.961023.

Bureau of Canadian Archivists. Canadian Archival Standard: Rules for Archival Description. Ottawa: Bureau of Canadian Archivists, 1990. http://www.cdncouncilarchives.ca/RAD/RADComplete July2008.pdf.

Carter, Anna. "Inspired by archives - fashion, textiles and the First World War." $A R C$ no. 326 (2016): 15-17.

Dever, Maryanne. "Photographs and manuscripts: working in the archive." Archives and Manuscripts 42, no. 3 (2014): 282-294. doi:10.1080/01576895.2014.956322.

Dever, Maryanne. "Provocations on the pleasures of archived paper." Archives and Manuscripts 41, no. 3 (2013): 173-182. doi:10.1080/01576895.2013.841550.

Dever, Maryanne, and Linda Morra. "Literary archives, materiality and the digital." Archives and Manuscripts 42, no. 3 (2014): 223-226. doi:10.1080/01576895.2014.966731.

Dudley, Sandra. "Encountering a Chinese horse: Engaging with the thingness of things." In Museum Objects: Experiencing the Properties of Things, edited by Sandra H. Dudley, 1-15. Abingdon: Routledge, 2012.

Duranti, Luciana. "Diplomatics: New Uses for an Old Science: Part I.” Archivaria 28 (1989): 7-27.

Eisenlohr, Patrick. "The anthropology of media and the question of ethnic and religious pluralism." Social Anthropology/Anthropologie Sociale 19, no 1 (2011): 40-55. doi:10.1111/j.1469-8676.2010.00136.x.

Farge, Arlette. The Allure of the Archives. Translated by Thomas Scott-Railton. New Haven: Yale University Press, 2013.

Gallagher, Shaun. How the Body Shapes the Mind. Oxford: Clarendon Press, 2005. 
Gell, Alfred. “Things' as social agents." In Museum Objects: Experiencing the Properties of Things, edited by Sandra H. Dudley, 336-343. Abingdon: Routledge, 2012.

Huizinga, Johan. "The Task of Cultural History." In Men and Ideas: History, the Middle Ages, the Renaissance: Essays by Johan Huizinga. Translated by James S. Holmes and Hans van Marle. London: Eyre and Spottiswoode, 1960, 17-76. Hull, Matthew. Government of Paper: The Materiality of Bureaucracy in Urban Pakistan. Berkeley: University of California Press, 2012.

Ingold, Tim. Lines: a brief history. Abingdon: Routledge, 2007.

International Council on Archives [ICA] Experts Group on Archival Description. Records in Contexts: A Conceptual Model for Archival Description, Consultation Draft v0.1. ICA, 2016. https://www.ica.org/sites/default/files/RiC-CM-0.1.pdf.

International Council on Archives [ICA] Experts Group on Archival Description. Records in Contexts (RiC): An Archival Description Draft Standard. ICA, 2016 [Presentation]. https://www.ica.org/sites/default/files/session-7.8-ica-egad-riccongress2016.pdf.

Kirshenblatt-Gimblett, Barbara. "The museum as catalyst.” Museums 2000: Confirmation of Challenge, Vadstena: ICOM, 2000. http://www.nyu.edu/classes/bkg/web/vadstena.pdf.

Lester, Peter. "Is the Virtual Exhibition the Natural Successor to the Physical?" Journal of the Society of Archivists 27, no. 1 (2006): 85-101.

MacLeod, Suzanne. "An Ethical Future for Museum and Gallery Design: design as a force for good in a diverse cultural sector." In The Future of Museum and Gallery Design, edited by S. MacLeod, J. Hale, T. Austin and O. Ho. London: Routledge, forthcoming.

Magee, Karl, and Susannah Waters. "Archives, Artists and Designers." Journal of the Society of Archivists 32, no. 2 (2011): 273-285.

Mak, Bonnie, and Pollack, Julia. "Book Unbound: An exploration of the material forms of the codex and e-book". Book 2.0, 3, no. 2 (2013): 137-147.

McGann, Jerome. "The Future is Digital.” Journal of Victorian Culture 13, no. 1 (2008): 80-88. 
Morphy, Howard. “Art as a mode of action: Some problems with Gell's Art and Agency." In Museum Objects: Experiencing the Properties of Things, edited by Sandra H. Dudley, 344-362. Abingdon: Routledge, 2012.

The National Archives. "Case Studies: Derbyshire Record Office. Working with an Artist in Residence." Accessed 18 October, 2017. http://www.nationalarchives.gov.uk/archives-sector/case-studies-and-researchreports/case-studies/sustainable-services/derbyshire-record-office/

The National Archives. "Case Studies: University of the Arts London." Accessed 18 October 2017. http://www.nationalarchives.gov.uk/archives-sector/case-studiesand-research-reports/case-studies/audience-development/university-of-the-artslondon/

O'Doherty, Brian. Inside the White Cube: The Ideology of the Gallery Space. Berkeley: University of California Press, 1986.

Pearce, Susan M. "Museum objects." In Museum Objects: Experiencing the Properties of Things, edited by Sandra H. Dudley, 23-25. Abingdon: Routledge, 2012.

Petit Palais Musée des Beaux-Arts de la Ville de Paris/French Ministry of Foreign Affairs and International Development. The Art of Peace: Secrets and Treasures of Diplomacy. [Exhibition]. Paris: Petit Palais, 19 October 2016 - 15 January 2017.

Petit Palais Musée des Beaux-Arts de la Ville de Paris/French Ministry of Foreign Affairs and International Development. The Art of Peace: Secrets and Treasures of Diplomacy. [Press release]. Paris: Petit Palais, 2016. http://www.petitpalais.paris/fr/en/expositions/art-peace.

Rekrut, Ala. "Matters of Substance: materiality and meaning in historical records and their digital images." Archives and Manuscripts 42, no. 3 (2014): 238-247. doi:10.1080/01576895.2014.958865.

Rekrut, Ala. "Material Literacy: Reading Records as Material Culture." Archivaria 60 (2005): 11-37.

Riles, Annelise. "In Response.” In Documents: Artifacts of Modern Knowledge, edited by Annelise Riles, 1-38. Ann Arbor: University of Michigan Press, 2006.

Sassoon, Rosemary. The Art and Science of Handwriting. Oxford: Intellect Books, 1993.

Stoler, Ann Laura. Along the Archival Grain: Epistemic Anxieties and Colonial Common Sense. Princeton: Princeton University Press, 2009. 
Takayanagi, Mari. “"New Dawn': archives as inspiration for art.” $A R C$, no. 325 (2016): 16-18.

Van de Wetering, Ernst. "The surface of objects and museum style." In Museum

Objects: Experiencing the Properties of Things, edited by Sandra H. Dudley, 103-108. Abingdon: Routledge, 2012.

Vismann, Cornelia. Files: Law and Media Technology. Stanford: Stanford University Press, 2008.

Williams, Caroline. "Diplomatic Attitudes: From Mabillon to Metadata." Journal of the Society of Archivists 26, no. 1 (2005): 1-24.

Zemon Davis, Natalie, "Forward." In Farge, Arlette. The Allure of the Archives, ix-xvi. New Haven: Yale University Press, 2013.

1. Petit Palais, Art of Peace [Press Release], 3.

2. "Diplomatic Treasures." Petit Palais, Art of Peace [Exhibition].

3. Duranti, "Diplomatics Part I," 15.

4. See Williams, "From Mabillon to Metadata," 6-7.

5. Dever, "Provocations," 176.

6. Ibid., 176-7.

7. Magee and Waters, "Archives, Artists and Designers," 277.

8. Vismann, Files, 39.

9. Ibid.

10. Ibid.

11. Dever, "Photographs and Manuscripts," 286.

12 See, for example, McGann, "The Future is Digital," 83; Mak and Pollack, "Book Unbound," 146; Rekrut, "Matters of Substance," 238-9. Natalie Zemon Davis, in her forward to the 2013 translation of Arlette Farge's The Allure of the Archives, originally published in 1989, notes the new lens through which Farge's account of her research experiences can now be examined in the light of increased digitization; see Davis, "Forward," xvi.

13. A useful summary of these and other observations is provided by Biber, "In Jimmy Governor's archive," 277. 
14. Dever, "Provocations," 174

15. Ibid.

16. Ibid., 174-5. See also Dever and Morra, "Literary archives," 223.

17. Dever, "Photographs and Manuscripts," 285

18. Ibid.

19. Dever, "Provocations," 175-6.

20. Eisenlohr, "The anthropology of media," 44.

21. Riles, "In Response," 21.

22. Mak and Pollack, "Book Unbound," 137.

23. Rekrut, "Matters of Substance," 238. See also Rekrut, "Material Literacy," 13.

24. Riles, "In Response,” 19.

25. Dudley, "Encountering a Chinese horse," 1, 2.

26. Ibid., 2-3.

27. Ibid., 2.

28. Hull, Government of Paper, 13.

29. Sassoon, Art and Science of Handwriting, 12.

30. Stoler, Along the Archival Grain, 20.

31. Shaun Gallagher discusses his work on the body and the mind by involving 'developmental, neurological, pathological, and phenomenological dimensions'. Gallagher, Body Shapes the Mind, 133.

32. Ibid., 134-5.

33. O'Doherty, Inside the White Cube, 61.

34. Gallagher, Body Shapes the Mind, 1.

35. Ibid., 26.

36. Ibid.

37. Ibid.

38. Ibid., 32-33. 
39. Ibid., 33-4. Gallagher gives the example of suffering from eye strain: attention is initially focused on the environment - the light, or the difficulty of the text - before the headache and fatigue assert themselves.

40. Ibid., 34.

41. Ibid., 151.

42. Ibid. Gallagher uses the example of a man's perception of a woman to illustrate this point.

43. MacLeod, "Ethical Future."

44. "Ratification par le président de la République du Pérou, Ramón Castilla y Marquesado, du traité d'amitié, de commerce et de navigation du 9 mars 1861, Lima, 10 décembre 1861." Petit Palais, Art of Peace [Exhibition].

45. Gallagher, Body Shapes the Mind, 8 .

46. Barbara Kirshenblatt-Gimblett discusses the concept of a performative museology, in which the museum, through a reflexive approach, itself becomes 'as a technology and as a medium in its own right, the subject'. Kirshenblatt-Gimblett, "The Museum as Catalyst," 11.

47. Gell, “"Things' as social agents,” 339.

48. Ibid., 338-9.

49. Morphy, "Art as mode of action," 358, n2.

50. Gell, “'Things' as social agents,” 339, 341-2.

51. Ibid., 342.

52. "Cartulaire de Christophe Colomb." Petit Palais, Art of Peace [Exhibition].

53. Ingold, Lines: a brief history, 143.

54. Huizinga, "Tasks of Cultural History," 54.

55. Ankersmit, Sublime Historical Experience, 121.

56. Van de Wetering, "Surface of objects," 105. See also Farge, Allure of the Archives, 8.

57. Pearce, "Museum objects," 24.

58. Bagnall, "Performance and performativity," 88.

59. Ibid., 87.

60. Dudley, "Encountering a Chinese horse," 11. 
61. Pearce, "Museum objects," 24; Lester, "Virtual Exhibition," 91.

62. The International Council on Archives' Records In Context Conceptual Model (RiC-CM), under development at the time of writing, does make reference to the physical components of the archival record; it includes scope for defining the documentary form of the record, connecting the model to diplomatics. ICA, Records in Context [Presentation], slide 22. In keeping with such an aim, much of the model's concern with the document's physical characteristics relates largely to their effect on the authenticity and reliability of the document, as well as the document's physical extent and condition. Its interest in the document's materiality, therefore, focuses on its role as a carrier of information. See ICA, Records in Contexts, 13, 18, 24. The Canadian Rules for Archival Description, through the specific inclusion of graphic and cartographic materials and architectural drawings, makes additional references to material forms: see Bureau of Canadian Archivists, Rules for Archival Description, sections 4.5C, 5.5C; 6.5C. Derbyshire Record Office provides an example of cataloguing practice which includes reference to archives' material properties. The National Archives, "Derbyshire Record Office", Outcomes paragraph 2. Examples of activities that place emphasis on the material form of archives include object based learning at the University of the Arts London (see The National Archives, "University of the Arts London") and West Yorkshire Archive Service's work with college students to create garments inspired by archives (see Carter, 'Inspired by Archives', 16). The material form of archives can also serve as inspiration for artists, as with the 'visual language of the Original Act rolls' at the Parliamentary Archives, for example, which influenced Mary Branson's New Dawn at the Houses of Parliament. Takayanagi, 'New Dawn', 16-7. 